Stephan G. Grimmelikhuijsen

Utrecht University, The Netherlands

Mary K. Feeney

Arizona State University

\title{
Developing and Testing an Integrative Framework for Open Government Adoption in Local Governments
}

\begin{abstract}
Open government is an important innovation to foster trustworthy and inclusive governments. The authors develop and test an integrative theoretical framework drawing from theories on policy diffusion and innovation adoption. Based on this, they investigate how structural, cultural, and environmental variables explain three dimensions of open government: accessibility, transparency, and participation. The framework is tested by combining 2014 survey data and observational data from 500 local U.S. government websites. Organizational structure, including technological and organizational capacity, is a determinant shared by all dimensions of open government. Furthermore, accessibility is affected by a mixture of an innovative and participative culture and external pressures. A flexible and innovative culture positively relates to higher levels of transparency, whereas capacity is a strong predictor of adopting participatory features. The main conclusion is that there is no one-size-fits-all solution to fostering the three dimensions of open government, as each dimension is subject to a unique combination of determinants.
\end{abstract}

\section{Practitioner Points}

- Open government adoption includes features such as accessibility, transparency, and participation.

- There is no one-size-fits-all solution to improving open government; each feature of open government is subject to a unique set of determinants.

- Adoption of open government features is more likely to succeed in less politicized environments, when there is ample technological capacity, and when there is a rather flexible and innovative working climate.

$\mathrm{O}$ pen government brings the promise of more transparent and trustworthy government (Bertot, Jeager, and Grimes 2010; Janssen, Charalabidis, and Zuiderwijk 2012). The Barack Obama administration even laid down principles in its Open Government Directive. Researchers have investigated various aspects of open government, such as computer-mediated transparency (Meijer 2009), website information provision (Grimmelikhuijsen and Welch 2012), financial transparency (Pina, Torres, and Royo 2010), and online participation (Feeney and Welch 2012; Ma 2014; Oliveira and Welch 2013). These studies provide insights to individual theoretical explanations for the extent of government accessibility, transparency, and participation.

More recently, scholars have suggested that open government is a multidimensional concept, including accessibility, transparency, and participation (cf. Abu-Shanab 2015; Linders 2012; Wirtz and Birkmeyer 2015), but because most research has separately investigated the dimensions of open government, our understanding of open government as a whole is fragmented. An integrative analysis of open government is important because connections between accessibility, transparency, and participation facilitate active citizenship. For example, if citizens can access government information, they can actively participate in decision-making processes (Meijer 2013; Meijer, Curtin, and Hillebrandt 2012). While there have been analyses of what dimensions make up open government (Abu-Shanab 2015; Linders 2012; Meijer, Curtin, and Hillebrandt 2012; Wirtz and Birkmeyer 2015), to the best of our knowledge, there have been no empirical studies on what factors determine open government as a whole.

The main contribution of this article is to develop and test an integrative approach to the potential determinants of open government. We draw on theories of policy innovation diffusion (Berry and Berry 1990) and innovation adoption (Damanpour 1991; Damanpour, Walker, and Avellaneda 2009; Rogers 2003) to better understand the determinants of open government. Our model incorporates the three main categories of determinants from the policy innovation diffusion and innovation adoption literatures: structural organizational variables, cultural organizational variables, and external environmental variables. Scholars have investigated these
Stephan G. Grimmelikhuijsen is assistant professor in the Utrecht University School of Governance in The Netherlands. His research interests include public sector transparency, citizen attitudes, e-government, and experimental and behavioral public administration. E-mail: s.g.grimmelikhuijsen@uu.nl

Mary K. Feeney is associate professor and Lincoln Professor of Ethics in Public Affairs at Arizona State University and associate director for the Center for Science, Technology and Environmental Policy Studies. Her research focuses on public and nonprofit management and science and technology policy. Her most recent book is Nonprofit Organizations and Civil Society in the United States (Routledge, 2014). E-mail: mkfeeney@asu.edu
Public Administration Review. Vol. 77, Iss. 4, pp. 579-590. @ 2016 by The American Society for Public Administration. DOI: 10.1111/puar. 12689. 
determinants to an extent-structural organizational determinants such as organizational resources (e.g., Bearfield and Bowman 2016; Grimmelikhuijsen and Welch 2012), organizational cultural variables (e.g., Oliveira and Welch 2013), and the external environment of an organization (e.g., Ma 2014). Our contribution is to theoretically integrate these broad categories and provide an empirical test of that framework for all three dimensions of open government. Our central research question is, to what extent do organizational structure, organizational climate, and organizational environment affect the adoption of open government features by local governments?

We test this framework for open government by combining two sources of data: a survey distributed to a national sample of department heads in 500 U.S. cities $(n=790)$ and objective data from a content analysis of the city websites. In general, analyzing websites on the presence of open government features is thought to be a sound measure of open government adoption, as the emergence of open government has been closely intertwined with the rapid development of information and communications technologies (ICTs). ICTs enable governments to collect, store, and release information on a large scale, which potentially fosters open government (e.g., Bertot, Jaeger, and Grimes; Meijer 2009). Indeed, new and old technologies are crucial to enabling open government (e.g., Abu-Shanab 2015; Linders 2012). Furthermore, many recent open government policy initiatives have a strong technical focus. For instance, Obama's Open Government Directive prescribes that government agencies have various data sets online (Obama 2009). The Open Government Partnership — an international collaboration of 69 countries devoted to improving open government policiesexplicitly encourages governments across the globe to "use innovations" and "new technologies" to "transform the culture of government and to serve the public better" (OGP 2015, 9). So although it is true that open government is broader than websites or other digital tools, the latter is regarded as a pillar in open government policy and research.

\section{Three Dimensions of Open Government}

The literature on government transparency often equates transparency with openness (Bertot, Jaeger, and Grimes 2010), the while decision-making literature specifies openness as access to decision-making arenas (Klijn et al. 2008). Drawing on these two literatures, Meijer, Curtin, and Hillebrandt argue that open government can refer to both types of openness in terms of information and participation, noting that open government is "the extent to which citizens can monitor and influence government processes through access to government information and access to decision-making arenas" $(2012,13)$.

For our definition of open government, we propose one alteration: that the access provided by open government includes a broader range of stakeholders, not just citizens, as specified in Meijer, Curtin, and Hillebrandt's (2012) definition. This group of stakeholders who would access information and decision-making arenas might also include journalists and interest groups. We use the following definition: open government is the extent to which external actors can monitor and influence government processes through access to government information and decision-making arenas.
Based on this definition, we distinguish three dimensions of open government: accessibility ("access"), transparency ("government information") and participation ("decision-making arenas"). Meijer, Curtin, and Hillebrandt (2012) analyze 103 articles on open government and find that it consists of two core components: (1) transparency, which is the "traditional" way of thinking about open government, that is, disclosure of information to the public; and (2) participation, or information disclosure that is necessary to participate in a meaningful way. This conceptualization is at odds with some of the recent literature, which notes an emerging consensus that collaboration is a separate dimension of open government (Wirtz and Birkmeyer 2015).

We do not include collaboration as a separate concept. Some participatory democracy scholars consider various features of collaboration to be forms of participation (Michels and de Graaf 2010). For instance, scholars define collaboration as active solicitation for citizen feedback (McDermott 2010) or active engagement of citizens in government (Wirtz and Birkmeyer 2015). However, there is little conceptual difference between this definition of collaboration and the way democratic theory has viewed participation. Participation not only encompasses political decisionmaking processes but also the workplace and local communities (Barber 1984; Michels and de Graaf 2010). Therefore, in line with the extant literature on participation and the conceptual distinction proposed by Meijer, Curtin, and Hillebrandt (2012), we focus primarily on participation, which includes features of collaboration, including informal ways of soliciting for feedback.

In this study, we consider accessibility as an underlying dimension of open government. Without proper access, transparency and participation are not possible. Meijer, Curtin, and Hillebrandt (2012) argue that open government refers to openness in terms of information, participation, and accessibility. Additionally, the interconnectedness between accessibility, transparency, and participation is noted in many policy documents, such as the Open Government Directive issued by President Obama. Therefore, it is crucial to take all three dimensions into account when investigating open government. We describe each dimension in more detail next.

Accessibility refers to the ability of all stakeholders to utilize information or participation options, both offline and online. However, we focus on online features of open government. Therefore, it is relevant to also consider the specific accessibility challenges for online open government features. For example, people with disabilities (e.g., hearing or visually impaired) or language barriers (e.g., translation of websites) should have access to information and participation options on websites. The literature on "digital divides" finds that online literacy, access, and tool use are influenced by socioeconomic status (SES). Lower-SES populations have lower online literacy, less secure access, less digital access at home, and higher reliance on smartphones or public Internet access (Mossberger, Tolbert, and Hamilton 2012).

Transparency refers to information provision to the public. Traditionally, transparency was related to direct openness, that is, making official meetings of legislatures accessible to the public so 
that people can assess government decision making. Transparency was practiced through the "old" information carrier, ink on paper, with the proceedings of official meetings written in minutes. Today, government organizations still provide information using leaflets or announcements in newspapers, but they increasingly use websites and social media outlets to post information (Cucciniello and Nasi 2014). We focus on the extent to which governments disclose information to external stakeholders through websites.

Participation refers to the extent to which governments allow external stakeholders to interact with them and is considered an important democratic feature. A classic example of participation is the town hall meeting. A different take on participation-which is more informal - is enabled by the use of technology: governments can ask stakeholders to provide input using Twitter or other social media channels (e.g., Grimmelikhuijsen and Meijer 2015). Many scholars claim that participation is positively related to the quality of democracy and improves the legitimacy of decisions (e.g., Porumbescu 2015). Thus, participation is embraced as one of the core dimensions of open government (Meijer, Curtin, and Hillebrandt 2012; Wirtz and Birkmeyer 2015). Interestingly, empirical findings consistently show that citizens have relatively little interest in participating and that active participants are not representative of the broader population (Michels and de Graaf 2010).

To overcome these problems of representativeness, accessibility, and interests, open government movements emphasize the use of websites and other digital tools to encourage, enhance, and facilitate participation in government dialogue and policy making. Particularly, the rise of social media use in the public sector has increased scholarly attention on online participation (Magro 2012; Mossberger, Wu, and Crawford 2013). The use of platforms such as Twitter and Facebook is thought to result in more transparency and citizen participation in government (Feeney and Welch 2012; Grimmelikhuijsen and Meijer 2015). Therefore, participation is an important dimension of open government.

\section{An Integrative Framework for Open Government}

Drawing from our discussion of the dimensions of open government (accessibility, transparency, and participation), we outline a framework for the determinants of open government. We draw on theories on policy innovation diffusion (Berry and Berry 1990) and innovation adoption (Damanpour 1991; Rogers 2003) to develop our propositions. Before outlining those theories and how they relate to our propositions, we discuss our working definition of innovation and how this relates to open government.

Studies of the adoption of innovation at the organizational level often define innovation as something new to the adopting organization (Walker 2008). Furthermore, a new idea can pertain to products, services, and administrative structures and processes (Damanpour, Walker, and Avellaneda 2009). Jun and Weare (2011) argue that innovation adoption is something that requires up-front expenditure of resources and a major departure from established routines. Open government qualifies as a type of innovation because it requires a departure from a more traditional logic.
Open government requires governments to proactively disclose information in an accessible way, ultimately enabling participation. It requires "up-front expenditure" to develop, monitor, and update websites and social media platforms. Finally, an element of risk is also involved, as openness comes with potential negative outcomes such as decreased trust (Grimmelikhuijsen et al. 2013) or disrupted policy processes (Feeney and Welch 2012; Welch and Feeney 2014). Hence, because open government introduces new technology, new relationships with stakeholders, and potential risks, we can consider it a form of public sector innovation.

But why do organizations innovate? One explanation is that organizations respond to pressures from the external environment, such as competition, resource scarcity, or citizen demands. A second reason is deliberate organizational decision making, for instance, to acquire new resources or distinctive competencies. The adoption of innovation is a way to adapt in order to maintain or improve organizational performance (Damanpour, Walker and Avellaneda 2009; Walker 2006). Likewise, local governments may respond to pressures from the environment to become more open, as there is a broad movement to pressure governments to become more accessible, transparent, and participatory (e.g., OGP 2015). In addition, adopting open government policies may help create better services. Our proposed framework incorporates three main categories of determinants that relate to the external environment and internal decision making: structural organizational variables, softer cultural organizational variables, and external environmental variables.

\section{Structural Organizational Determinants}

The first structural determinant of innovation adoption is organizational capacity (Damanpour 1991). Organizations with higher capacity can more easily afford innovations and have more freedom to experiment with innovations. Furthermore, prior research recognizes the importance of capacity for the development, maintenance, and smooth functioning of e-government initiatives, which may not be equal to but are related to open government. For instance, research has found that organizational capacity is positively related to e-government implementation and progress (Moon 2002; Moon and Norris 2005). $\mathrm{Ma}$ (2014) uses municipal wealth and size to gauge organizational capacity and finds that these are positively and significantly correlated with the number of government microblogs in China-furthering evidence that capacity is critical to open government initiatives. Given these findings, we expect that open government adoption will be positively related to organizational capacity.

Proposition 1: Organizational capacity will be positively related to open government.

Second, we investigate technological capacity. The technological expertise and capabilities available in an organization might be crucial to furthering open government (Meijer 2009; Wirtz and Birkmeyer 2015). A core concept in government use of technology is the stages models for e-government (Gil-Garcia 2012; Layne and Lee 2001), which argue that in order to attain full openness and participation, governments must progress from basic to more advanced technologies. 
The presence of e-services is one of the early or middle stages of e-government adoption and thus is important. E-services include the provision of services and transactions such as allowing residents to register to vote or complete financial transactions such as paying tickets or fines. Governments that have well-developed e-services demonstrate a basic level of technological capacity and effort. Thus, technological capacity, measured as e-services, is expected to be positively related to open government because the use of technology to inform and involve citizens is a pillar of various open government initiatives (Wirtz and Birkmeyer 2015).

Proposition 2: Higher levels of technological capacity (presence of e-services) will be positively related to the adoption of open government.

Third, we consider centralization, a concept that describes centralized decision making in organizations (Hall 1963). Centralized organizations are characterized by centralized reporting, processes, decision making, and control and are expected to limit the contribution that individual employees can make through their work, as individuals are expected to follow centralized processes. According to a widely cited meta-analysis by Damanpour (1991), centralization has a negative effect on innovation adoption. Similarly, Mergel and Bretschneider (2013) hypothesize that decentralized decision making fosters social media adoption because this allows individuals to experiment with innovations. When decision making is highly centralized, it is likely that there is less room for experimentation with new technologies that facilitate participation, making it less likely for centralized organizations to be accessible and transparent. Thus, we hypothesize the following:

Proposition 3: Higher levels of organizational centralization will be negatively related to the adoption of open government.

\section{Cultural Organizational Determinants}

A category of determinants of adoption of open government that is often overlooked in the literature is the "softer" organizational determinants (Greenhalgh et al. 2004; Korteland and Bekkers 2008). In a comprehensive literature review on organizational innovation, Greenhalgh et al. (2004) find that dimensions such as the prevailing culture in an organization and attitudes toward risk taking can influence innovation adoption. We take these findings into account by including work routineness, innovation-oriented climate, and citizen participation climate in our study. These three determinants all relate to the extent to which an organizational culture is flexible and open to unexpected events.

Work routineness is characterized by low task variety and sameness in work activities on a day-to-day basis (Lee, Rainey, and Chun 2010). Work routineness is often related to jobs with lower levels of professional education and organizational structures that require less analyzability and problem solving. Because open government facilitates interactions with government constituents, it may conflict with other organizational routines. Furthermore, work routineness is often related to risk aversion; a civil servant in an organization with strong work routineness will experience a stable work environment and may be less used to risk taking. Indeed, Wirtz et al. (2015) find that the perceived risk-based attitude of civil servants can be a barrier to adopting open government data policies. Thus, we expect the following:
Proposition 4: Work routineness will be negatively related to the adoption of open government.

Innovation-minded organizational climates are more likely to accept innovations (Feeney and Welch 2012; Moon and Norris 2005; Oliveira and Welch 2013). Innovation-oriented cultures are typically defined by their receptiveness to new ideas (Wynen, Ongaro, and Van Thiel 2014). While Kim and Bretschneider (2004) link innovation orientations and climates to e-government adoption, the literature on this link is scarce. Moon and Norris (2005) argue that innovation-oriented governments tend to adopt new managerial and technological approaches faster. Specifically, governments that implement such innovations fervently have a prevailing innovationminded culture. Overall, this makes these governments more likely to see the value of innovations such as open government initiatives and enable them to adopt these with less resistance. Recently, Oliveira and Welch (2013) found that innovation-minded cultures are more likely to use social media to disseminate information and to enable participation. Therefore, we postulate the following:

Proposition 5: A climate that is more conducive to innovation will be positively related to adoption of open government.

The third cultural element we consider is the organization's likeliness to be open to external stakeholders. For organizations to adopt open government, they need to use various enabling technologies such as social media and websites. However, such tools are not a silver bullet to engaging the public (Grimmelikhuijsen and Meijer 2015); engagement requires an organizational culture that supports openness of citizen participation. A culture of openness toward external stakeholders also enables learning and better adaption to the environment (Mahler 1997), thus increasing the likeliness of open government adoption. Furthermore, a culture of transparency and openness is necessary to have a real impact on government (Bertot, Jaeger, and Grimes 2010). To our knowledge, the specific effect of a "culture of openness" on open government adoption has not been investigated in the literature thus far. Therefore, we postulate the following:

Proposition 6: An organizational climate that is more conducive to openness will be positively related to the adoption of open government.

\section{Determinants in the Organizational Environment}

Much of the research investigating the adoption and diffusion of policy innovations draws from institutional theory: organizations sometimes adopt innovations as a way to adapt to their environment and legitimize their existence (e.g., Damanpour, Walker and Avellaneda 2009; DiMaggio and Powell 1983). Based on institutional theory, Berry and Berry (1990) develop a theory on how policy innovations "diffuse" across states. According to this theory, competition, normative pressure, coercion, and learning are mechanisms that cause states to adopt policies developed in other jurisdictions. These processes have found further external validation in later studies (e.g., Lee, Chang, and Berry 2011; Shipan and Volden 2008). Next we explain how each part of the Berry and Berry model might apply to the adoption of open government.

Competition. Implementing innovations such as open government lends public support and indicates that a government organization 
is "modern" and "makes sense" (DiMaggio and Powell 1983;

Korteland and Bekkers 2008). Conversely, governments that do not remain competitive and adopt innovations at the same rate will lag their peers. Ma (2014) demonstrates that horizontal competition was positively associated with the adoption of government microblogging in China. This resonates in recent empirical findings by Bearfield and Bowman (2016), who find that large cities are driven by competition to become more transparent. In line with the literature, we expect that governments will be driven by open government competition and will be more likely to adopt social media technologies when peer cities are doing the same.

Proposition 7: Competitive pressures from peer cities will be positively related to the adoption of open government.

Coercive Pressures. A second determinant of innovation adoption is coercive pressures. Coercive regulations and vertical political mandates exert pressure on governments to adopt particular innovations (Berry and Berry 2007; DiMaggio and Powell 1983; Shipan and Volden 2008). In this case, U.S. municipal governments often fall under policies, rules, and regulations from higher levels of government such as states and the federal government, which serve as coercive pressures. Additionally, some local government agencies such as police and transportation departments may fall under professional and national standards and regulations with regard to policing and road building, respectively. Bryson et al. (2013) highlight that in order to fit participatory policies to the environment, it is important to clarify legal requirements and observe freedom of information laws for the public. We capture coercive pressures by looking at whether an organization is required to adhere to a law or regulation about engaging the public in decision making.

Proposition 8: Coercive pressures for public participation will be positively related to the adoption of open government.

Normative Pressures. Normative pressures - the culmination of common practices, values, and norms - can be external or internal to the organization and are typically exerted by relevant government constituents (Berry and Berry 2007; Lee, Chang, and Berry 2011). In the case of open government, individuals and organizations that are using online technologies and want to use the tools to interact with government most prominently exert external normative pressure for government adoption (Ma 2014). However, there are other relevant constituents that use open government, most notably, individuals, community organizations, business, or media who might seek transparency or participatory tools to track, monitor, and report government actions. For instance, research shows that stakeholder pressure can influence website transparency (Bearfield and Bowman 2016; Grimmelikhuijsen and Welch 2012). Thus, we postulate the following:

Proposition 9: Increased influence from external stakeholders will be positively related to the adoption of open government.

There are also internal normative pressures for open government. The decision to adopt open government, and especially the participation dimension, might derive from personal use of social networking services (SNS). As of 2015, use of SNS is quite high. The Pew Research Center reports that 65 percent of American adults use SNS and that this use affects politics, work, communication patterns, civic life, health, access to information, parenting, dating, and other outcomes (Perrin 2015). Individuals who are already using the technologies associated with open government in their personal lives might be more likely to advocate for these technologies in the workplace. We argue that individuals who are avid users of social media platforms will be more likely to push for technological adoption in the organization, or at the very least, they will have less resistance to new technologies in their departments.

Proposition 10: Personal social media use will be positively related to the adoption of online open government.

Learning. Learning can be described as governments adopting innovations by observing the experiences of nearby jurisdictions (Shipan and Volden 2008). The line between learning and competition is not always clear. According to Shipan and Volden (2008), learning focuses on the policy itself, how is it effective, and how can it be effectively implemented. In comparison, competition is more strongly focused on imitation of a peer government, identifying what a certain competitor does and trying to do the same. In comparison, learning occurs across organizations that are not necessarily at the same level (Lee, Chang, and Berry 2011; Ma 2014) but can learn with relative ease in geographic or cultural terms.

Proposition 11: Governments that are able to learn from other organizations will be positively related to the adoption of online open government.

Political Environment. Our final proposition regards the political environment. Political competition is a core construct that may influence the adoption of open government (cf. Grimmelikhuijsen and Welch 2012). Political competition could foster stronger open government because when incumbents face uncertainty over future political power - which is the case in a competitive environmentthey seek to ensure future access by increasing access to government information (Berliner and Erlich 2015). On the other hand, a more politicized environment could also hamper openness. For instance, in the U.S. mayor-council type, governments are highly politicized and have elected mayors with strong executive powers, such as controlling budgets and appointing key officials including judges, police chiefs, and so on. Manager-council governments, in comparison, have elected councils that hire a professional city manager to steer the city (Zhang and Feiock 2010). Recent findings suggest that administrative professionalism influences transparency of local governments, particularly in smaller cities (Bearfield and Bowman 2016). Furthermore, an experimental study by de Fine Licht (2014) finds that transparency in more politicized policy arenas is more likely to result in less public support. Overall, the empirical evidence indicates that less political environments are more likely to adopt of open government features.

Proposition 12: Governments in less politicized environments will have increased adoption of online open government. 


\section{Methodology \\ Data Collection and Analysis}

We use three data sources: a 2014 national survey of U.S. city government managers, observational data collected from 500 local government websites, and U.S. Census data. The survey was conducted by the Center for Science, Technology, and Environmental Policy Studies at Arizona State University. The sampling frame draws from managers working in 500 U.S. cities with populations ranging from 25,000 to 250,000 . The frame includes all cities with populations of 100,000 to 250,000 and a random sample of cities with populations of 25,000 to 100,000. The survey was administered to individuals holding five positions in each city — city manager/city administrator, director of community and/or economic development, finance director, director of parks and recreation, deputy police chief - using Sawtooth Software from April 7, 2014, to June 6, 2014. The survey was administered to an adjusted sample of 2,442 individuals, ${ }^{1}$ with 790 completed responses. The American Association for Public Opinion Researchcalculated response rate is 33.29 percent: 790 responses from 2,373 known eligible cases. Weights for the data were calculated based on respondent city size (the sampling procedure).

The observational data come from the websites of the 500 cities in the sample. Two coders used an identical protocol to identify 19 key functionalities on each website. The coding was conducted from April 2014 through June 2014. An intercoder reliability test resulted in the retention of 17 of the coded items. A third coder, the principal investigator, verified the remaining 17 items with a spot check of consistent codes and broke ties between inconsistent codes.

The unit of analysis is the survey respondent, who was asked to respond to a series of questions about his or her work environment (e.g., the department). The individual responses were then paired with census data for the city, region, and state and the codes from the website content analysis. We calculated four linear regression models - one for each dimension of open government and one for all dimensions simultaneously—in which we included variables to measure 11 of the 12 propositions. We also included variables to control for population and department.

\section{Variables and Measures}

\section{Dependent Variables. We measure the adoption of open}

government using content analysis of 500 city government websites. The protocol instructed three coders to look only at content that was no more than three links away from the homepage, ensuring that only easily accessible content was measured. All codes were based on a three-clicks search. Coders were allowed to use the search bar, but only if the end content was still within three clicks of the home page. The researchers coded the same 500 websites in two stages. First, two researchers worked independently to code all 500 websites. After conducting an intercoder reliability analysis, the principal investigator eliminated two of the items (federal government link and press release) from the data set (because of inconsistent coding and low kappa scores) and then reconciled the remaining codes.

It is important to note that one limitation of the content analysis is that the codes indicate the presence of a service and not the quality of that service or how often it is used. We do not know whether the service is mediocre or advanced or how citizens feel about accessibility, usability, and functionality. Table 1 shows which items we used to calculate sum scores for the three dimensions of open government: accessibility, transparency, and participation.

Independent Variables. We use a number of independent variables to capture the concepts outlined in the propositions. Scales constructed of multiple survey items are detailed in table 2 and briefly described in this section. Organizational capacity (proposition 1) is measured using a natural log of the city population. We acknowledge that city size is not a perfect measure for organizational capacity, although it is often argued in the literature on technology adoption that larger governments have the advantage of having a greater administration, more slack, and more resources than smaller cities (e.g., Moon 2002). In a similar vein, we use city population as a proxy for organizational capacity (see, e.g., Damanpour 1991; Ma 2014).

Technological capacity (proposition 2) is measured using a sum score of five items from the website content analysis: (1) online completion and submission of job applications, (2) online employment information (e.g., openings and application

Table 1 Intercoder Reliability for Dependent Variables

\begin{tabular}{|c|c|c|}
\hline Variable & Description & Kappa \\
\hline \multicolumn{3}{|l|}{ Accessibility } \\
\hline NonEnglish & Provides access for non-English speakers & .893 \\
\hline RSS & There is an RSS feed & .838 \\
\hline Searchbar & There is a searchable database/search bar & .937 \\
\hline SearchProvider & Search bar by outside provider (e.g., Google or Bing) & .899 \\
\hline \multicolumn{3}{|l|}{ Transparency } \\
\hline DeptDescription & $\begin{array}{l}\text { Provides description of activities of municipal } \\
\text { departments/agencies/units; description should be } \\
\text { on a central site/directory rather than having to go } \\
\text { to departments }\end{array}$ & .791 \\
\hline Directory & $\begin{array}{l}\text { Central directory with all employees listed with } \\
\text { contact information; not just directors but also an } \\
\text { employee directory that enables citizens to find a } \\
\text { particular person }\end{array}$ & .786 \\
\hline Districtmaps & Provides maps of council districts & .813 \\
\hline FOIA & $\begin{array}{l}\text { Freedom of Information Act/FOIA is mentioned or } \\
\text { there is a link to or text of public information law; } \\
\text { this includes records requests }\end{array}$ & .838 \\
\hline Lawlndex & $\begin{array}{l}\text { Provides a searchable index or list for archived laws, } \\
\text { regulations, and requirements; includes municipal } \\
\text { code }\end{array}$ & .657 \\
\hline MajorSpeech & $\begin{array}{l}\text { Text or video of major speeches of mayor or chief } \\
\text { executive or city council chair (or president or } \\
\text { head) }\end{array}$ & .837 \\
\hline Meetingvideo & $\begin{array}{l}\text { Online video, audio podcast, video webcast, or live } \\
\text { feed of council meetings }\end{array}$ & .791 \\
\hline SiteContract & $\begin{array}{l}\text { Statement or advertisement declaring that the site } \\
\text { is development or maintained by an outside } \\
\text { contractor }\end{array}$ & .927 \\
\hline Votinglnfo & Provides information on voting and/or elections & .880 \\
\hline \multicolumn{3}{|l|}{ Participation } \\
\hline Blog & There is a blog, discussion board, or forum & .697 \\
\hline ContactMayor & $\begin{array}{l}\text { Provides contact information for mayor: e-mail, } \\
\text { phone, address }\end{array}$ & .671 \\
\hline CouncilAgenda & Council meeting agendas are posted & .772 \\
\hline Facebook & There is a "Follow us on Facebook" link & .914 \\
\hline Twitter & There is a "Follow us on Twitter" link & .893 \\
\hline VotingRegister & $\begin{array}{l}\text { Provides forms for voter registration (direct link to } \\
\text { county or state also counts) }\end{array}$ & .842 \\
\hline Youtube & There is a YouTube link & .883 \\
\hline
\end{tabular}




\begin{tabular}{|c|c|c|}
\hline Scale & $\begin{array}{c}\text { Cronbach's } \\
\text { Alpha }\end{array}$ & Questionnaire Items \\
\hline Centralization & 0.79 & $\begin{array}{l}\text { 1. There can be little action taken here until a } \\
\text { supervisor approves a decision. } \\
\text { 2. In general, a person who wants to make his } \\
\text { own decisions would be quickly discouraged } \\
\text { in this agency. } \\
\text { 3. Even small matters have to be referred to } \\
\text { someone higher up for a final answer. }\end{array}$ \\
\hline Competition & $\mathrm{n} / \mathrm{a}$ & $\begin{array}{l}\text { Does your organization use social media for any } \\
\quad \text { purpose? } \\
\text { 1. Facebook (no/yes) } \\
\text { 2. Twitter (no/yes) } \\
\text { 3. YouTube (no/yes) } \\
\text { 4. Linkedln (no/yes) } \\
\text { Sum scores of these for items were used to } \\
\text { calculate means for nine population size } \\
\text { categories. }\end{array}$ \\
\hline Routineness & 0.63 & $\begin{array}{l}\text { 1. People here do the same job in the same way } \\
\text { every day. } \\
\text { 2. One thing people like around here is the } \\
\text { variety of work. (R) } \\
\text { 3. Most jobs have something new happening } \\
\text { every day. (R) }\end{array}$ \\
\hline Innovativeness & 0.83 & $\begin{array}{l}\text { 1. This organization has a strong commitment } \\
\text { to innovation. People who develop innovative } \\
\text { solutions to problems are rewarded. } \\
\text { 2. This organization is a very dynamic and } \\
\text { entrepreneurial place. People are willing to } \\
\text { stick their necks out and take risks. } \\
\text { 3. Employees in this organization are rewarded } \\
\text { for developing innovative solutions to } \\
\text { problems. } \\
\text { 4. Most employees in this organization are not } \\
\text { afraid to take risks. }\end{array}$ \\
\hline Openness & 0.80 & $\begin{array}{l}\text { 1. People in this organization believe that } \\
\text { citizen participation is necessary even if } \\
\text { it dramatically slows down government } \\
\text { decisions. } \\
\text { 2. People in this organization believe that citizen } \\
\text { participation actually increases government } \\
\text { effectiveness. } \\
\text { 3. People in this organization believe it is the } \\
\text { government's responsibility to fully integrate } \\
\text { citizens in its deliberation and decision } \\
\text { processes. }\end{array}$ \\
\hline
\end{tabular}

Response categories: Five-point Likert scale of agreement, 1 = strongly agree, $5=$ strongly disagree.

procedures), (3) ability to file police reports online (includes graffiti reporting), (4) ability to register and pay for classes online, and (5) direct link or access to transactional opportunities such as paying bills or parking tickets. In each case, the items were coded 1 if the feature was present on the website, 0 if not.

Centralization (proposition 3) is measured using the average of responses to three questionnaire items (Hall 1963). The Cronbach's alpha for the centralization scale is 0.79 .

Routineness (proposition 4) is measured by averaging responses to three items asking respondents about work routineness (Hall 1963). The routineness scale has a Cronbach's alpha of 0.63 , which is sufficient because the scale consists of three items. Innovative climate (proposition 5) is measured using an average of responses on four items and has a Cronbach's alpha of 0.83 . Openness to participation (proposition 6) is measured as the averaged responses to the three questionnaire items and has a Cronbach's alpha of 0.80 .
Competition (proposition 7) is measured by calculating the average open government score for peer cities, defined as being the same size. We coded the 500 cities into nine groups based on population: lowest through 49,999; 50,000-74,999; 75,000-99,999; 100,000-124,999; 125,000-174,999; 175,000-199,999; 200,000-224,999; and 225,000-250,000. For each set of cities, we calculated a perceived open government score based on the survey data. Questions can be found in table 2. The mean open government score was then coded as a separate variable for each respondent. So, for instance, a respondent from a city with 70,000 inhabitants would be coded with the open government mean of the cities with a population of 50,000 to 74,999. Thus, peer open government scores are an indicator of competition from similarly sized cities. A higher average in a "peer category" is an indicator of higher competition to have more advanced and open websites.

Coercive pressures (proposition 8), pressure that forces or obligates behaviors, is measured using responses to the following question: "Is your organization legally required to include citizen input in policy-making activities?" ( $1=$ yes, $0=$ no). External public pressures (proposition 9) is calculated as the average of responses to four questionnaire items that asked respondents how often the following four groups participated in decision making: individual citizens, neighborhood associations, news media, and interest groups (Cronbach's alpha $=0.80)$. Response categories used a five-point scale ranging from $1=$ very often to $5=$ never.

To assess a respondent's internal norms (proposition 10) toward innovation and participation, we asked how often the respondent uses social media to (1) communicate with work colleagues and (2) communicate with friends or family. The measure is the average response from a five-point scale $(1=$ several times an hour; $2=$ several times a day; 3 = about once a day; $4=$ every few days; $5=$ less often or never) and has Cronbach's alpha of 0.72 .

We had no fitting measure for learning (proposition 11) in our data. Various studies have shown that a link between learning and policy adoption exists (Shipan and Volden 2008), and subsequent research could aim to develop concrete measures to test this proposition in the context of open government.

To measure the political environment (proposition 12), we use data from the International City/County Management Association and website searches to code the type of government for each city: council-manager (0) and mayor-council (1).

We controlled for department type using a set of dummy variables: mayor's office, parks and recreation, police, community development, finance, and police.

\section{Results}

Table 3 shows the descriptive statistics for all the variables in the regression equation. Table 3 indicates that there are missing data for the coercive pressure variable; 694 out of 790 respondents completed this question. This question asked whether the participant's organization was legally required to include citizen input in policymaking activities. Seventy-nine participants (10 percent) indicated they did not know whether this was the case. We used pairwise deletion of cases in the regression analyses so as not to lose all of these cases and thus statistical power. 
Table 4 shows that the correlations between the independent variables are in the expected directions: see, for instance, the negative correlation between centralization and innovativeness $(R=-.414)$, the positive correlation between centralization and work routineness $(R=.448)$, and the strong relationship between some of the environmental pressures (e.g., coercive and external pressures, $R=.344$ ). None of the correlations in table 4 indicates multicollinearity; however, the correlation between competition and organizational capacity is relatively high $(R=.806)$. This can be explained by the fact that we used city size as a proxy for organizational capacity: larger cities are more likely to have larger government agencies and capacity for servicing larger populations but also because they are likely to feel more pressure from competition as they are more visible to the public (Bearfield and Bowman 2016). Furthermore, although a coefficient of .806 is high, the ordinary least squares regression analysis results presented in table 5 indicate there is no multicollinearity in our models.

First we review the findings for the separate models predicting accessibility, transparency, and participation. A combination of the

Table 3 Descriptive Statistics

\begin{tabular}{lccccc}
\hline & Min. & Max. & Mean & SD & N \\
\hline Organizational capacity & 10.13 & 12.39 & 10.90 & 0.55 & 790 \\
Technological capacity & 1 & 5 & 3.39 & 1.19 & 790 \\
Centralization & 1 & 5 & 2.41 & 0.74 & 724 \\
Innovativeness & 1 & 5 & 3.16 & 0.80 & 732 \\
Routineness & 1 & 5 & 3.46 & 0.65 & 724 \\
Openness to participation & 1 & 5 & 3.55 & 0.79 & 771 \\
Competition & 2.81 & 3.63 & 2.91 & 0.13 & 790 \\
External pressure & 1 & 5 & 3.25 & 0.87 & 768 \\
Internal norms & 1 & 5 & 1.42 & 0.74 & 769 \\
Coercive pressure & 0 & 1 & 0.44 & 0.50 & 694 \\
Political environment: Mayor- & 0 & 1 & 0.27 & 0.45 & 790 \\
$\quad$ council & & & & & \\
Mayor's office & 0 & 1 & 0.17 & 0.38 & 790 \\
Community development & 0 & 1 & 0.25 & 0.43 & 790 \\
Finance & 0 & 1 & 0.17 & 0.38 & 790 \\
Parks and recreation & 0 & 1 & 0.20 & 0.40 & 790 \\
Police & 0 & 1 & 0.21 & 0.41 & 790 \\
Accessibility & 0 & 4 & 2.08 & 1.00 & 790 \\
Transparency & 1 & 9 & 4.47 & 1.64 & 790 \\
Participation & 0 & 7 & 4.44 & 1.32 & 790 \\
Online open government (all) & 1 & 15 & 9.47 & 2.54 & 790 \\
\hline
\end{tabular}

Table 4 Correlation Matrix

\begin{tabular}{|c|c|c|c|c|c|c|c|c|c|c|c|c|c|c|}
\hline & 1 & 2 & 3 & 4 & 5 & 6 & 7 & 8 & 9 & 10 & 11 & 12 & 13 & 14 \\
\hline $\begin{array}{l}\text { 1. Organizational capacity } \\
\text { (city size) }\end{array}$ & 1 & & & & & & & & & & & & & \\
\hline 2. Technological capacity & $.275^{\star \star}$ & 1 & & & & & & & & & & & & \\
\hline 3. Centralization & .006 & $-.128^{* *}$ & 1 & & & & & & & & & & & \\
\hline 4. Innovativeness & $.078^{*}$ & $.124^{* *}$ & $-.414^{\star \star}$ & 1 & & & & & & & & & & \\
\hline 5. Work routineness & -.038 & $-.181^{\star *}$ & $.448^{* \star}$ & $-.394^{\star *}$ & 1 & & & & & & & & & \\
\hline $\begin{array}{l}\text { 6. Openness to } \\
\text { participation }\end{array}$ & .006 & .070 & $-.121^{\star *}$ & $.246^{* *}$ & $-.191^{\star *}$ & 1 & & & & & & & & \\
\hline 7. Competition & $.806^{\star \star}$ & $.216^{\star *}$ & -.006 & .042 & -.040 & -.011 & 1 & & & & & & & \\
\hline 8. External pressure & $.108^{* *}$ & $.148^{* *}$ & .003 & $.090^{*}$ & $-.126^{* *}$ & $.407^{* *}$ & $.0990^{* *}$ & 1 & & & & & & \\
\hline 9. Internal norms & .017 & -.030 & -.015 & $.099^{* \star}$ & $-.094^{*}$ & -.011 & .012 & .023 & 1 & & & & & \\
\hline 10. Coercive pressure & .048 & .060 & .058 & .009 & -.006 & $.283^{* \star}$ & .045 & $.344^{\star \star}$ & -.035 & 1 & & & & \\
\hline $\begin{array}{l}\text { 11. Political environment } \\
(\text { mayor-council = 1) }\end{array}$ & .016 & $-.340^{* *}$ & $.127^{\star \star}$ & -.035 & $.080^{*}$ & .040 & .016 & $.082^{*}$ & $.073^{*}$ & .037 & 1 & & & \\
\hline 12. Accessibility & $.215^{\star *}$ & $.342^{* *}$ & $-.076^{\star}$ & $.139^{\star *}$ & -.071 & $.127^{\star \star}$ & $.142^{\star \star}$ & $.165^{* \star}$ & .033 & -.001 & $-.138^{\star \star}$ & 1 & & \\
\hline 13. Transparency & $.150^{\star *}$ & $.250^{* \star}$ & -.026 & $.104^{\star *}$ & .017 & .018 & $.148^{\star *}$ & $.082^{*}$ & -.064 & $.091^{*}$ & $-.143^{* \star}$ & $.277^{\star \star}$ & 1 & \\
\hline 14. Participation & $.320^{\star \star}$ & $.419^{\star \star}$ & -.046 & .068 & $-.077^{\star}$ & $.095^{\star \star}$ & $.252^{\star \star}$ & $.137^{\star \star}$ & -.010 & .030 & $-.192^{\star *}$ & $.369^{\star \star}$ & $.356^{\star \star}$ & 1 \\
\hline
\end{tabular}

Pearson correlation coefficients.

${ }^{*} p<.05 ;{ }^{*} p<.01$.

586 Public Administration Review • July|August 2017 three factors (organizational structure, culture, and environment) influences accessibility. For example, accessibility is higher in governments with more organizational $(\beta=.191)$ and technological capacity $(\beta=.264)$. Furthermore, accessibility is higher with organizational climates that are conducive to participation $(\beta=.094)$. External pressures from citizens, interest groups, and news media are also positively related to online accessibility $(\beta=.123)$.

A combination of factors influence website transparency, including technological capacity and organizational culture. An organizational climate conducive to innovation is positively related to website transparency $(\beta=.126)$ and negatively related to work routineness $(\beta=-.106)$. This aligns with our expectation that organizations with daily routines are less likely to be innovative. Furthermore, the political environment is a significant predictor of the adoption of open government. As we expected, mayor-council governments tend to be less transparent than council-manager governments $(\beta=-.087)$.

Technological capacity is a strong predictor of participation $(\beta=.312)$. In addition, organizational capacity is significantly associated with participation $(\beta=.238)$. Surprisingly, none of the cultural variables is associated with the adoption of participation practices. From the environmental variables, only mayor-council governments tend to be less developed in terms of online participation opportunities $(\beta=-.099)$.

The fourth regression model, presented in table 5 , shows the results for the combined open government adoption. The model indicates that e-services are strongly and positively related to adoption of open government $(\beta=.366)$. External public pressures ( $\beta=.091)$ make open government adoption more likely. Councilmanager systems tend to have stronger open government presence $(\beta=-.107)$. We also observe that organizational climates affect open government adoption, either positively by an innovative climate $(\beta=.072)$ or negatively by high routineness $(\beta=-.081)$.

The variance explained by our model is reasonable for participation (23.8 percent), moderate for accessibility (17.2 percent), and low for transparency ( 10.5 percent). The fourth model, which takes the means of all three dimensions together, has an explained variance of 29.9 percent. 
Table 5 Regression Models for Accessibility, Transparency, Participation, and Combined Construct

\begin{tabular}{|c|c|c|c|c|}
\hline & Accessibility & Transparency & Participation & Open Government (all) \\
\hline Organizational capacity (size) & $0.191 * *$ & 0.019 & $0.238^{* * \star}$ & $0.207^{* * *}$ \\
\hline Technological capacity & $0.264 * * *$ & $0.188 * * *$ & $0.312 * * *$ & $0.376 * * *$ \\
\hline Centralization & -0.007 & 0.007 & 0.010 & -0.024 \\
\hline Routineness & -0.072 & $-0.106^{*}$ & -0.007 & $-0.081 *$ \\
\hline Innovativeness & $0.072+$ & $0.126 * *$ & -0.011 & $0.073^{+}$ \\
\hline Participation & 0.094 & -0.039 & 0.068 & 0.055 \\
\hline Competition & -0.081 & 0.084 & -0.008 & -0.011 \\
\hline Coercive pressure & -0.044 & $0.084^{+}$ & -0.030 & 0.001 \\
\hline External pressure & $0.123 * *$ & 0.049 & 0.064 & $0.093^{*}$ \\
\hline Internal norms & 0.029 & -0.061 & 0.000 & -0.012 \\
\hline Mayor-council & $-0.068^{+}$ & $-0.087^{*}$ & $-0.099 * *$ & $-0.108 * *$ \\
\hline \multicolumn{5}{|l|}{ Control variables } \\
\hline Mayor's office & -0.061 & -0.004 & 0.014 & -0.018 \\
\hline Community development & $-0.105+$ & -0.038 & -0.030 & -0.078 \\
\hline Finance & -0.071 & -0.003 & 0.013 & -0.021 \\
\hline \multirow[t]{4}{*}{ Parks and Recreation } & -0.042 & 0.016 & 0.002 & -0.012 \\
\hline & $F=8.72^{\star \star \star}$ & $F=4.92^{\star \star \star}$ & $F=13.11^{\star \star \star}$ & $F=17.97^{\star \star \star}$ \\
\hline & $R^{2}=.172$ & $R^{2}=.105$ & $R^{2}=.238$ & $R^{2}=.299$ \\
\hline & Adj. $R^{2}=.152$ & Adj. $R^{2}=.083$ & Adj. $R^{2}=.220$ & Adj. $R^{2}=.283$ \\
\hline
\end{tabular}

$+p<.1 ;{ }^{*} p<.05 ; * * p<.01 ; * * * p<.001$.

Standardized beta coefficients are displayed.

All variables have variance inflation factors of 3.0 or lower, which indicates there is no or very little multicollinearity.

Pairwise deletion of missing values

Reference category for departments: Police department

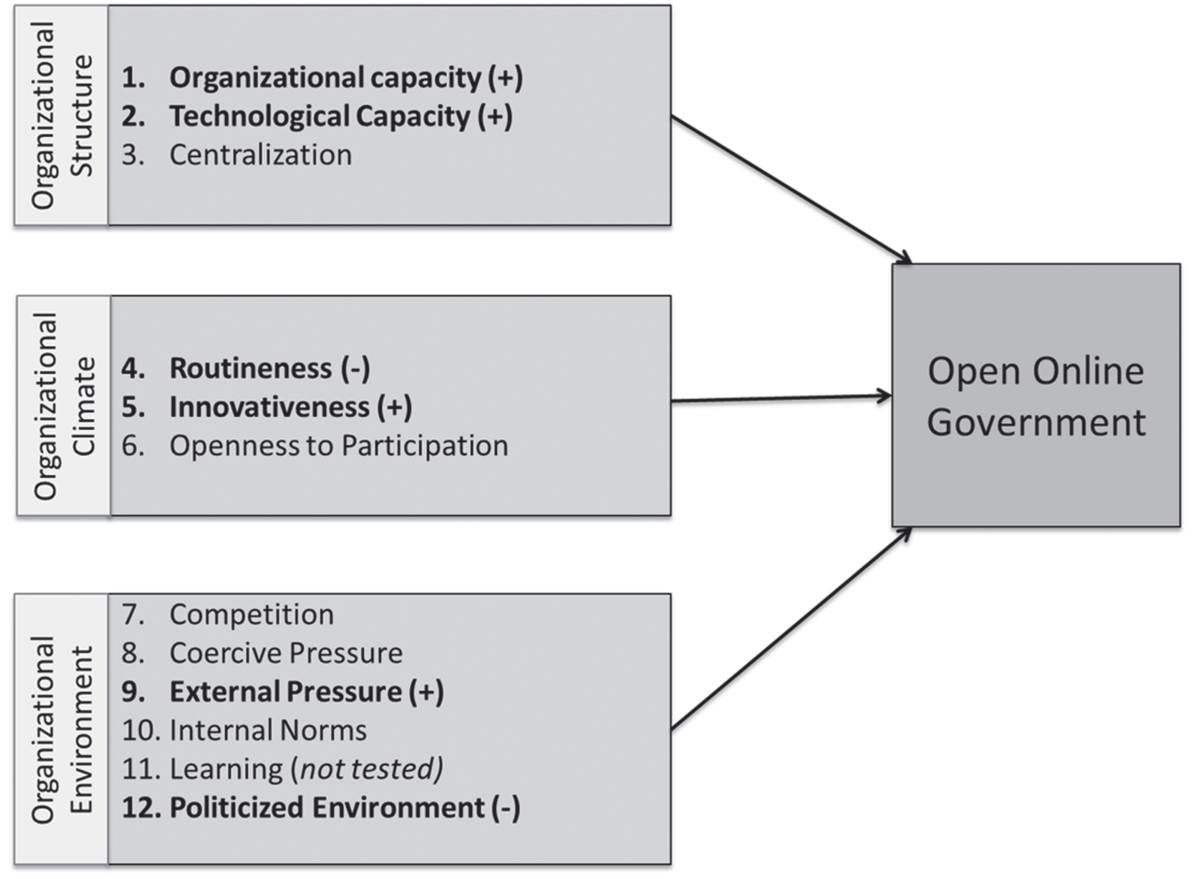

Figure 1 Framework for Explaining Open Online Government

Figure 1 presents the overall empirical findings as they relate to our framework for investigating the ways in which organizational structure, culture, and environment are related to open government. We find that technological capacity is positively related to open government. This is in line with the idea that if a strong online infrastructure is present, it is easier to facilitate open government through digital channels. Furthermore, organizational capacity is related to open government, while centralization is not significant in the empirical model.

Second, the organizational cultural variables have a heterogeneous effect on open government as the effect varies across dimensions.
We find a marginally negative significant relationship between work routineness and accessibility and a slightly stronger relationship with transparency, whereas participation is unrelated. The figures for innovativeness are opposite that for work routineness, that is, a marginal but positive association with accessibility and bit stronger relationship with transparency. Openness to participation is not related to transparency, but it is positively related to accessibility and online participation.

Third, organizational environment is related to open government. The political environment shows the clearest relation: small cities in a mayor-council system tend to have less open websites than cities 
with a council-manager system. Furthermore, external pressures are weakly significantly related to accessibility and marginally related to participation. Other variables-competition, internal norms, and coercive pressures—are not significantly related to open government.

\section{Discussion}

This research is one of the first empirical tests of the determinants of open government, a concept that comprises previously disconnected literatures on government accessibility, transparency, and participation. We find that a mixture of structural, cultural, and environmental forces shape open government. This mixture of factors shows that an integrative framework for open government has value. We cannot get a full picture of open government determinants using only structural, cultural, or environmental factors. From the structural organizational perspective, technological and organizational capacity are more strongly related to open government. From a cultural point of view, organizations with high work routineness are less likely to adopt open government practices. Furthermore, the political environment and the extent to which individual citizens, neighborhood associations, news media, and interest groups are involved in decision making (reflecting external pressures) are positively associated with open government.

Furthermore, we find that there are distinct drivers for each dimension of open government. First, accessibility is fostered in climates that value openness and are under pressure by external stakeholders. Second, transparency seems best fostered in a culture without strong work routineness, as it has more flexibility. Civil servants in such an environment may be better equipped to deal with transparency because disclosing information can cause unpredictable responses among the public (e.g., Grimmelikhuijsen and Kasymova 2016; Wirtz et al. 2015). Third, participation is prevalent when there is ample organizational and technological capacity in combination with a less political environment. Technological capacity is particularly important for participation because the resources to continuously and actively involve external stakeholders are high. Governments require resources to start and maintain conversation with citizens and stakeholders.

Overall, technological capacity is an important determinant across all three dimensions. Our study may somewhat overestimate the effect of technological capacity on open government and is limited by the method by which we measure and operationalize technological capacity. That said, this finding aligns with earlier findings that technological capacity is a determinant of open government (e.g., Ma 2014; Moon 2002), and we do not find empirical evidence that the relationship is endogenous.

Organizational climate has a heterogeneous effect, which is an important finding because research on open government and innovation thus far has not paid much attention to the influence of these "softer" organizational determinants (Greenhalgh et al. 2004; Korteland and Bekkers 2008). Furthermore, the organizational environment influences open government adoption. This resonates with the literature on government transparency, which has found that external pressures matter (Grimmelikhuijsen and Welch
2012; Relly and Sabharwal 2009) and that the council-manager structure - the less political form of local government-tends to be more transparent (Bearfield and Bowman 2016).

We propose five modifications for future research. First, we find no relation between centralization and open government adoption. We suspect that the relationship between centralization and adoption is not as straightforward for open government as it is for the adoption of other innovations (Damanpour 1991). The adoption of open government is a highly complex organizational and political process and may benefit from a centralized structure. For instance, centralized decision-making power could help make bolder decisions to adopt and advance open government.

Second, although recent research finds a relationship between competition and social media (Ma 2014) and e-government adoption (Lee, Chang, and Berry 2011), we do not find a relationship between our measure of competition with peer cities and open government adoption. One substantive explanation for this is that open government may not be an item for competition; it is not a simple innovative "gadget" that can easily be emulated. According to Shipan and Volden (2008), competition is focused on imitating a peer government, identifying what a certain competitor does, and trying to do the same, which may not fit the complexity of open government adoption. An alternative explanation is that our measure of competition is too limited. Because this variable is based on population categories, this measure is partly collinear with the population control variable. This measure could be improved to better gauge the influence of organizational environment, for instance, by assessing mayoral or employee participation in state, regional, or national conferences open government.

Third, an important limitation of our empirical analysis is that we do not have measures for learning, a component of our framework for open government. Future studies may consider focusing on how (local) governments learn from each other in implementation, accessibility, transparency, and participation practices.

Fourth, coercive pressures apparently have no influence. However, we acknowledge that we used a limited measure. The coercive pressure measure consisted of one question asking whether the respondent's organization was subject to some kind of law that required citizen input in decision making. However, this measure did not specify whether this obligation only applied to offline participation or also online participation. A more precise measure could improve the model.

A final improvement is to further explore how the political environment affects open government. We have one measure of the political environment (type of government). Future research would benefit from additional political measures that might affect open government such as political competition, government ideology, and past government's experience with open government. Political competition (e.g., Berliner and Erlich 2015) and ideology (e.g., Grimmelikhuijsen and Welch 2012) have already been found to affect government transparency and may affect other dimensions of open government too. Future research might consider these iterations to improve our understanding of open government adoption. 


\section{Conclusion}

The main contribution of this article is to develop and test an integrative framework for the determinants of open-accessible, transparent, and participative-government. To our knowledge, this is the first study to empirically test such an integrative model for open government. Much more is to be done to further assess our framework. Five specific suggestions to improve the construct validity are already mentioned in the Discussion section. In addition, we need more research to assess the external validity of our findings. Most importantly, our framework was tested in the U.S. context. and it is unclear whether our findings hold across different institutional and cultural contexts. Following prior research on transparency, it is likely that shared determinants such as organizational and technological capacity also matter in very different cultural contexts (e.g., Piotrowski et al. 2009), yet it is less certain that findings also hold for the "softer" cultural and environmental determinants.

Our main conclusion is that there is no one-size-fits-all solution to fostering the three dimensions of open government, as each dimension is subject to a unique combination of determinants. For instance, transparency is best fostered in innovative and less bureaucratic organizational cultures, participation is most likely to be present in local governments with a great deal of organizational and technological resources, and external pressures are important for accessibility. Organizational capacity, technological capacity, and a depoliticized environment are shared determinants.

Finally, this article shows the added value of integrating the potential determinants of open government innovation in a framework integrating structural, cultural, and environmental perspectives. We cannot get a full picture of open government determinants by looking only at organizational structure, culture, or the environment. As governments are under increasing pressure to be more open, both online and offline, it will be critical to recognize the role that strong technological and organizational capacity, innovative cultures, low work routineness, external pressures, and depoliticized environments play to become more open.

\section{Acknowledgments}

This article was presented at a workshop during the Global Conference on Transparency Research, 2015, held in Lugano. We thank the participants, particularly Albert Meijer, for their feedback.

\section{Note}

1. A total of 69 surveys were returned undelivered and categorized as "unknown eligibility." The sample was adjusted for 58 cases that were not eligible: 2 e-mail addresses were unavailable, 37 individuals in the sample were no longer working in the position or had retired, and 19 individuals were serving in more than one position in the city.

\section{References}

Abu-Shanab, Emad A. 2015. Reengineering the Open Government Concept: An Empirical Support for a Proposed Model. Government Information Quarterly 32(4): 453-63.

Barber, Benjamin R. 1984. Strong Democracy: Participatory Politics for a New Age. Berkeley: University of California Press.

Bearfield, Domonic A., and Ann O'M. Bowman. 2016. Can You Find It on the Web? An Assessment of Municipal E-Government Transparency. American
Review of Public Administration. Published electronically on February 1. doi:10.1177/0275074015627694.

Berliner, Daniel, and Aaron Erlich. 2015. Competing for Transparency: Political Competition and Institutional Reform in Mexican States. American Political Science Review 109(1): 110-28.

Berry, Frances Stokes, and William D Berry. 1990. State Lottery Adoptions as Policy Innovations: An Event History Analysis. American Political Science Review 84(2): 395-416.

2007. Innovation and Diffusion Models in Policy Research. In Theories of the Policy Process, 3rd ed., edited by Paul A. Sabatier, and Christopher M. Weible, 223-60. Boulder, CO: Westview Press.

Bertot, John C., Paul T. Jaeger, and Justin M. Grimes. 2010. Using ICTs to Create a Culture of Transparency: E-Government and Social Media as Openness and AntiCorruption Tools for Societies. Government Information Quarterly 27(3): 264-71.

Bryson, John M., Kathryn S. Quick, Carissa Schively Slotterback, and Barbara C. Crosby. 2013. Designing Public Participation Processes. Public Administration Review 73(1): 23-34.

Cucciniello, Maria, and Greta Nasi. 2014. Transparency for Trust in Government: How Effective Is Formal Transparency? International Journal of Public Administration 37(13): 911-21.

Damanpour, Fariborz. 1991. Organizational Innovation: A Meta-Analysis of Effects of Determinants and Moderators. Academy of Management Journal 34(3): 555-90.

Damanpour, Fariborz, Richard M. Walker, and Claudia N. Avellaneda. 2009. Combinative Effects of Innovation Types and Organizational Performance: A Longitudinal Study of Service Organizations. Journal of Management Studies 46(4): 650-75.

de Fine Licht, Jenny. 2014. Policy Area as a Potential Moderator of Transparency Effects: An Experiment. Public Administration Review 74(3): 361-71.

DiMaggio, Paul J., and Walter W. Powell. 1983. The Iron Cage Revisited: Institutional Isomorphism and Collective Rationality in Organizational Fields. American Sociological Review 48(2): 147-60.

Feeney, Mary K., and Eric W. Welch. 2012. Electronic Participation Technologies and Perceived Outcomes for Local Government Managers. Public Management Review 14(6): 815-33.

Gil-Garcia, J. Ramon. 2012. Enacting Electronic Government Success: An Integrative Study of Government-Wide Websites, Organizational Capabilities, and Institutions. New York: Springer.

Greenhalgh, Trisha, Glenn Robert, Fraser Macfarlane, Paul Bate, and Olivia Kyriakidou. 2004. Diffusion of Innovations in Service Organizations: Systematic Review and Recommendations. Milbank Quarterly 82(4): 581-629.

Grimmelikhuijsen, Stephan G., and Jyldyz Kasymova. 2016. Not So Universal After All: Exploring the Meaning and Use of Government Transparency in Consensual and Majoritarian Democracies. Public Integrity 17(4): 389-407.

Grimmelikhuijsen, Stephan G., and Albert J. Meijer. 2015. Does Twitter Increase Perceived Police Legitimacy? Public Administration Review 75(4): 598-607.

Grimmelikhuijsen, Stephan G., Gregory Porumbescu, Boram Hong, and Tobin Im. 2013. The Effect of Transparency on Trust in Government: A Cross-National Comparative Experiment. Public Administration Review 73(4): 575-86.

Grimmelikhuijsen, Stephan G., and Eric W. Welch. 2012. Developing and Testing a Theoretical Framework for Computer-Mediated Transparency of Local Governments. Public Administration Review 72(4): 562-71.

Hall, Richard H. 1963. The Concept of Bureaucracy: An Empirical Assessment. American Journal of Sociology 69(1): 32-40.

Janssen, Marijn, Yannis Charalabidis, and Anneke Zuiderwijk. 2012. Benefits, Adoption Barriers and Myths of Open Data and Open Government. Information Systems Management 29(4): 258-68.

Jun, Kyu-Nahm, and Christopher Weare. 2011. Institutional Motivations in the Adoption of Innovations: The Case of E-Government. Journal of Public Administration Research and Theory 21(3): 495-519. 
Kim, Hyun Joon, and Stuart Bretschneider. 2004. Local Government Information Technology Capacity: An Exploratory Theory. In Proceedings of the 37th Hawaii International Conference on System Sciences. Washington, DC: IEEE Computer Society Press.

Klijn, Erik-Hans, Jurian Edelenbos, Michiel Kort, and Mark J.W. van Twist. 2008. Facing Management Dilemmas: An Analysis of Managerial Choices in 18 Complex Environmental Public-Private Partnership Projects. International Review of Administrative Sciences 74(2): 251-82.

Korteland, Evelien, and Victor J. J. M. Bekkers. 2008. The Diffusion of Electronic Service Delivery Innovations in Dutch E-Policing: The Case of Digital Warning Systems. Public Management Review 10(1): 71-88.

Layne, Karen, and Jungwoo Lee. 2001. Developing Fully Functional E-Government: A Four Stage Model. Government Information Quarterly 18(2): 122-36.

Lee, Chung-pin, Kaiju Chang, and Frances Stokes Berry. 2011. Testing the Development and Diffusion of E-Government and E-Democracy: A Global Perspective. Public Administration Review 71(3): 444-54.

Lee, Jung Wook, Hal G. Rainey, and Young Han Chun. 2010. Goal Ambiguity, Work Complexity, and Work Routineness in Federal Agencies. American Review of Public Administration 40(3): 284-308.

Linders, Dennis. 2012. From E-Government to We-Government: Defining a Typology for Citizen Coproduction in the Age of Social Media. Government Information Quarterly 29(4): 446-54.

Ma, Liang. 2014. Diffusion and Assimilation of Government Microblogging: Evidence from Chinese Cities. Public Management Review 16(2): 274-95.

Magro, Michael J. 2012. A Review of Social Media Use in E-Government. Administrative Sciences 2(2): 148-61.

Mahler, Julianne. 1997. Influences of Organizational Culture on Learning in Public Agencies. Journal of Public Administration Research and Theory 7(4): 519-40.

McDermott, Patrice. 2010. Building Open Government. Government Information Quarterly 27(4): 401-13.

Meijer, Albert J. 2009. Understanding Computer-Mediated Transparency. International Review of Administrative Sciences 75(2): 255-69.

- 2013. Understanding the Complex Dynamics of Transparency. Public Administration Review 73(3): 429-39.

Meijer, Albert J., Deirdre Curtin, and Maarten Hillebrandt. 2012. Open Government: Connecting Discourses on Transparency and Participation. International Review of Administrative Sciences 78(1): 10-29.

Mergel, Ines, and Stuart Bretschneider. 2013. A Three-Stage Adoption Process for Social Media Use in Government. Public Administration Review 73(3): 390-400.

Michels, Ank, and Laurens de Graaf. 2010. Examining Citizen Participation: Local Participatory Policy Making and Democracy. Local Government Studies 36(4): 477-91.

Moon, M. Jae. 2002. The Evolution of E-Government among Municipalities: Rhetoric or Reality? Public Administration Review 62(4): 424-33.

Moon, M. Jae, and Donald F. Norris. 2005. Does Managerial Orientation Matter? The Adoption of Reinventing Government and E-Government at the Municipal Level. Information Systems Journal 15(1): 43-60.

Mossberger, Karen, Caroline J. Tolbert, and Allison Hamilton. 2012. Measuring Digital Citizenship: Mobile Access and Broadband. International Journal of Communication 6: 2492-2528.
Mossberger, Karen, Yonghong Wu, and Jared Crawford. 2013. Connecting Citizens and Local Governments? Social Media and Interactivity in Major U.S. Cities. Government Information Quarterly 30(4): 351-58.

Obama, Barack. 2009. Transparency and Open Government. Memorandum for the Heads of Executive Departments and Agencies. http://www.whitehouse. gov/the_press_office/TransparencyandOpenGovernment [accessed May 9, 2016].

Oliveira, Gustavo Henrique Maultasch, and Eric W. Welch. 2013. Social Media Use in Local Government: Linkage of Technology, Task, and Organizational Context. Government Information Quarterly 30(4): 397-405.

Open Government Partnership (OGP). 2015. Star Reforms in the Open Government Partnership. http://www.opengovpartnership.org/sites/default/files/ attachments/Star\%20Commitments_0.pdf [accessed May 7, 2016].

Perrin, Andrew. 2015. Social Media Usage: 2005-2015. Pew Research Center, October 8. http://www.pewinternet.org/2015/10/08/social-networkingusage-2005-2015/ [accessed October 16, 2016].

Pina, Vicente, Lourdes Torres, and Sonia Royo. 2010. Is E-Government Promoting Convergence Towards More Accountable Local Governments? International Public Management Journal 13(4): 350-380.

Piotrowski, Suzanne J., Yahong Zhang, Weiwei Lin, and Wenxuan Yu. 2009. Key Issues for Implementation of Chinese Open Government Information Regulations. Public Administration Review 69(1): 129-35.

Porumbescu, Gregory A. 2015. Using Transparency to Enhance Responsiveness and Trust in Local Government: Can It Work? State and Local Government Review 47(3): 205-13.

Relly, Jeannine E., and Meghna Sabharwal. 2009. Perceptions of Transparency of Government Policymaking: A Cross-National Study. Government Information Quarterly 26(1): 148-57.

Rogers, Everett M. 2003. Diffusion of Innovations, 5th ed. New York: Simon \& Schuster.

Shipan, Charles R., and Craig Volden. 2008. The Mechanisms of Policy Diffusion. American Journal of Political Science 52(4): 840-57.

Walker, Richard M. 2008. An Empirical Evaluation of Innovation Types and Organizational and Environmental Characteristics: Towards a Configuration Framework. Journal of Public Administration Research and Theory 18(4): 591-615.

Welch, Eric W., and Mary K. Feeney. 2014. Technology in Government: How Organizational Culture Mediates Information and Communication Technology Outcomes. Government Information Quarterly 31(4): 506-12.

Wirtz, Bernd W., and Steven Birkmeyer. 2015. Open Government: Origin, Development, and Conceptual Perspectives. International Journal of Public Administration 38(5): 381-96.

Wirtz, Bernd W., Robert Piehler, Marc-Julian Thomas, and Peter Daiser. 2015. Resistance of Public Personnel to Open Government: A Cognitive Theory View of Implementation Barriers towards Open Government Data. Public Management Review 18(9): 1335-64.

Wynen, Jan, Koen Verhoest, Eduardo Ongaro, and Sandra van Thiel. 2014. Innovation-Oriented Culture in the Public Sector: Do Managerial Autonomy and Result Control Lead to Innovation? Public Management Review 16(1): 45-66.

Zhang, Yahong, and Richard C. Feiock. 2010. City Managers' Policy Leadership in Council-Manager Cities. Journal of Public Administration Research and Theory 20(2): 461-76. 